\title{
Associação entre fatores de risco cardiovascular e proteina C-reativa em mulheres idosas
}

\author{
Association between cardiovascular risk factors and C-reactive protein in aged women
}

Fernanda Blauth'; Gustavo M. Lara²; Sandrine C. Wagner²; César L.Reichert'2,

\begin{abstract}
unitermos
Proteína C-reativa

Idoso

Mulheres

\section{resumo}

Introdução: O processo inflamatório desempenha um importante papel na etiologia das doenças cardiovasculares. Muitos estudos demonstram que níveis elevados de proteína C-reativa (PCR), uma proteína hepática de fase aguda, estão associados ao risco de tais eventos. Objetivos: Investigar a existência de associação entre PCR e fatores de risco cardiovascular em mulheres idosas. Material e método: Foram realizadas avaliações antropométricas, impedanciometria, verificação de pressão arterial, mensurações de perfil lipídico, glicemia em jejum e PCR. Resultados: Observou-se que a PCR esteve relacionada com índice de massa corporal $(p=0,001)$ e com percentual de gordura corporal $(p=0,015)$, não apresentando relação significativa com nenhuma outra variável estudada. Discussão: $A$ associação entre PCR e marcadores de obesidade é consenso na literatura, podendo, no entanto, não significar verdadeira progressão da aterosclerose ou de um estado inflamatório. Em relação à inexistência de associação com os demais fatores de risco cardiovascular observada neste estudo, os dados encontrados são conflitantes. Há autores que indicam a correlação entre PCR e tais fatores; outros apontam sua inexistência. Conclusões: Este trabalho demonstra a associação da PCR a marcadores de obesidade, mas não a outros fatores de risco cardiovascular.
\end{abstract}

\section{abstract}

Background: The inflammatory process plays an important role in the etiology of cardiovascular diseases. Several studies have shown that high levels of $\mathrm{C}$-reactive protein (CRP), a hepatic acute phase protein, are associated with the risk of such diseases. Objectives: In this study we investigated the existence of association between CRP and cardiovascular risk factors in elderly women. Material and method: Anthropometric data, body impedance, blood pressure, lipid profiles, fasting glucose and CRP levels were evaluated. Results: We observed that CRP was linked with body mass index $(p=0.001)$ and body fat percentage $(p=0.015)$ and there was no significant connection with any other studied variable. Discussion: The association between CRP and measures of obesity is a consensus in literature. However, it may not show a true progression of atherosclerosis or an inflammatory state. Regarding the inexistence of association with other cardiovascular risk factors observed in this study, the gathered data are conflicting. Some authors indicate correlation between $P C R$ and such factors, whereas others point out its inexistence. Conclusions: This study demonstrates the association of CRP with obesity, but not with other cardiovascular risk factors. key words

C-reactive protein

Cardiovascular disease

Elderly women

1. Biomédica do Centro Universitário Feevale.

2. Professores-mestre do Curso de Biomedicina do Centro Universitário Feevale.

3. Programa de Pós-graduação em Geriatria da Pontifícia Universidade Católica do Rio Grande do Sul (PUCRS). 


\section{Introdução}

Atualmente existem muitas evidências sobre o papel do processo inflamatório na fisiopatogenia da aterosclerose, sendo amplamente aceito que a inflamação em nível endotelial é o seu fator desencadeador ${ }^{(16,23)}$. Níveis plasmáticos de marcadores inflamatórios, particularmente a proteína C-reativa (PCR), mostram-se preditivos para angina instável, infarto do miocárdio e morte súbita em indivíduos adultos e idosos, com ou sem doença cardiovascular (DCV) estabelecida, com mais eficiência do que poderia ser estimado pelos fatores de risco tradicionais $(5,9,12,14,19,24,28)$. A PCR é uma proteína hepática, produzida sob estímulo da interleucina 6 (II-6), que desempenha papel primordial na resposta imune inata humana ${ }^{(8,27)}$.

Há mais de 60 anos se tem conhecimento da ligação da PCR a lípides e a lipoproteínas plasmáticas, mas a primeira sugestão de uma possível ligação à aterosclerose veio com a observação de que a proteína se liga seletivamente à lipoproteína de baixa densidade (LDL) $)^{(13)}$. A partir de então, vários estudos vêm demonstrando a relação entre os níveis de PCR e a morbimortalidade associada às $\operatorname{DCVs}_{S}(4,15,17$, 21). O papel biológico dessa proteína ainda não está totalmente esclarecido, mas sabe-se que ela é capaz de ativar o sistema complemento e que está relacionada com efeitos pró-coagulantes ${ }^{(23)}$. Especula-se ainda que a PCR possa ter significativos efeitos pró-inflamatórios e que, ao se ligar a moléculas expostas nas células (resultantes de infecção, inflamação, isquemia e outras patologias) e desencadear a ativação do complemento, ela possa exacerbar o dano tecidual ${ }^{(18)}$. A PCR elevada pode refletir maior formação de placas ateroscleróticas, maior tendência a ruptura da placa e trombose ${ }^{(29)}$. Estudos longitudinais, nos quais homens $\mathrm{e}$ mulheres aparentemente saudáveis foram acompanhados por três a oito anos, mostraram que a PCR está associada a risco de eventos cardíacos, independentemente de níveis lipídicos, tabagismo e índice de massa corporal $(\mathrm{IMC})^{(7)}$. Recentemente, o Centers for Disease Control and Prevention (CDC) e a American Heart Association (AHA) estabeleceram que indivíduos adultos com valores de PCR $>3 \mathrm{mg} / \mathrm{l}$ têm risco cardiovascular duas vezes maior que pessoas com níveis $<1 \mathrm{mg} / /^{(14)}$. Existem numerosos estudos contrários ou favoráveis à utilização da PCR como ferramenta preditiva de eventos cardiovasculares ${ }^{(1,2,20,22)}$. Porém, se os níveis elevados da PCR estiverem intimamente ligados aos fatores de risco convencionais, a mensuração desse marcador não será de grande valor para os clínicos ${ }^{(13)}$. O objetivo deste estudo foi determinar a existência de associação entre fatores de risco cardiovascular e níveis de PCR em mulheres idosas.

\section{Material e método}

\section{Recrutamento das participantes e avaliação dos fatores de risco cardiovascular}

Participaram deste projeto 119 mulheres com 60 anos de idade ou mais, residentes na cidade de Novo Hamburgo (RS), sem histórico de DCVs ou qualquer processo infeccioso ou inflamatório em curso. Essas mulheres foram selecionadas de uma amostra inicial, do tipo probabilístico, calculada com $95 \%$ de confiabilidade e margem de erro máxima de 5\%, representativa do município. Assinado o termo de consentimento, as participantes preencheram um questionário abordando aspectos gerais de saúde. Em seguida foram submetidas a avaliação antropométrica, verificação de pressão arterial (PA) (por esfigmomanômetro aneróide previamente calibrado) e impedanciometria (pelo equipamento Tetrapolar Maltron BF-900). Com base nos padrões antropométricos, calculou-se o índice de massa corporal $\left(\mathrm{IMC}=\right.$ peso $\mathrm{kg} /$ altura $\left.\mathrm{m}^{2}\right)$.

As amostras sangüíneas foram colhidas por meio de punção venosa e distribuídas em tubos com gel separador (para obtenção do soro) e em outros contendo fluoreto de sódio (específicos para mensuração de glicemia). As dosagens de glicemia em jejum (G)), colesterol total (CT), colesterol da lipoproteína de alta densidade (HDL-C) e triglicérides (TG) foram realizadas pelo método enzimático-colorimétrico segundo Trinder (Labtest), com prévia precipitação de lipoproteína de densidade muito baixa (VLDL) e LDL para a determinação de HDL. O LDL-C foi obtido pela equação de Friedewald (para TGs $<400 \mathrm{mg} / \mathrm{dl}$ ).

Consideraram-se com sobrepeso indivíduos com IMC entre 25 e $29,9 \mathrm{~kg} / \mathrm{m}^{2}$, e obesos com IMC a partir de $30 \mathrm{~kg} / \mathrm{m}^{2}$. Para as demais variáveis foram utilizados os seguintes valores de referência como critério de normalidade: medida de cintura $<88 \mathrm{~cm}$; PA sistólica (PAS) $<120 \mathrm{mmHg}$ e diastólica (PAD) < $80 \mathrm{mmHg} ; \mathrm{G}$ ) $<100 \mathrm{mg} / \mathrm{dl}$; CT $<200 \mathrm{mg} / \mathrm{dl}$; $\mathrm{HDL}-\mathrm{C}>50 \mathrm{mg} / \mathrm{dl} ; \mathrm{LDL}-\mathrm{C}<160 \mathrm{mg} / \mathrm{dl} ; \mathrm{TGs}<150 \mathrm{mg} / \mathrm{dl}$. Considerando não haver, na literatura pesquisada, valores consensuais quanto ao percentual de gordura corporal em idosos, optou-se por apenas descrevê-los.

O projeto de pesquisa foi previamente aprovado pelo Comitê de Ética em Pesquisa da Pontifícia Universidade Católica do Rio Grande do Sul (PUCRS), segundo ofício de número 099/05, e desenvolvido integralmente conforme os princípios éticos estabelecidos na Resolução no 196/96 do Conselho Nacional de Saúde (CNS). 


\section{Mensuração e classificação da PCR}

O soro das participantes foi mantido sob congelamento a $-20^{\circ} \mathrm{C}$ até o momento do processamento. A técnica utilizada foi a turbidimétrica para PCR de alta sensibilidade, realizada conforme protocolo do kit CRP-us (Diasys), no equipamento Cobas Mira Plus (Roche). Os níveis de PCR foram classificados em baixo risco cardiovascular para valores $<1 \mathrm{mg} / \mathrm{l}$, risco moderado para valores entre $1 \mathrm{mg} / \mathrm{l} \mathrm{e}$ $3 \mathrm{mg} / \mathrm{l}$ risco elevado para valores $>3 \mathrm{mg} / /^{(14,17)}$. Amostras $>$ $10 \mathrm{mg} / \mathrm{l}$ foram excluídas por sugerirem processo infeccioso ou inflamatório agudo $(n=5)^{(14)}$.

\section{Análise estatística}

Os procedimentos estatísticos utilizaram como metodologia testes de correlação, estatística descritiva e análise de variância (ANOVA) fator único, utilizando o software SPSS, versão 12.0. Foi considerado significativo $p<0,05$ e muito significativo $p<0,01$.

\section{Resultados}

As características gerais das participantes deste estudo podem ser observadas na Tabela 1. Note-se que a média dos indivíduos apontou sobrepeso, elevação na PAS e na $P A D$, níveis aumentados de CT e diminuídos de HDL-C. Não houve relato de tabagismo.

Entre as participantes deste estudo, 29 (25,4\%) apresentaram níveis de PCR indicando baixo risco cardiovascular; $43(37,7 \%)$, risco moderado; e $42(36,8 \%)$, risco elevado,
Características gerais apresentadas pelas

Tabela 1 participantes do estudo $(n=114)$

\begin{tabular}{lc}
\hline Variáveis & Média \pm desvio padrão \\
\hline Idade (anos) & $67,8 \pm 5,7$ \\
IMC (kg/m²) & $28,6 \pm 4,9$ \\
Gordura corporal (\%) & $42,4 \pm 8,7$ \\
Cintura (cm) & $87,6 \pm 13,3$ \\
PA (mmHg) & \\
- sistólica & $142,6 \pm 25,4$ \\
- diastólica & $84,9 \pm 16$ \\
Glicemia de jejum (mg/dl) & $87,6 \pm 18,9$ \\
Colesterol (mg/dl) & \\
• total & $208,5 \pm 42,2$ \\
• HDL & $45,8 \pm 10,7$ \\
- LDL & $133,4 \pm 43,3$ \\
Triglicérides (mg/dl) & $146,7 \pm 73,2$ \\
PCR (mg/l) & $2,63 \pm 2,07$ \\
\hline
\end{tabular}

IMC: índice de massa corporal; PA: pressão arterial; HDL: lipoproteína de alta densidade; LDL: lipoproteína de baixa densidade; PCR: proteína C-reativa.

como indica a Tabela 2. As variáveis avaliadas estão apresentadas de forma estratificada, de acordo com os níveis de risco cardiovascular sinalizados pela PCR.

Verificando-se a Tabela 3, observa-se a existência de correlação entre PCR e IMC, bem como entre PCR e percentual de gordura corporal. As demais variáveis apresentaram correlações não significativas.

Tabela 2 Características das participantes do estudo, estratificadas de acordo com níveis de PCR mensurada

\begin{tabular}{lcccc}
\hline Variáveis & PCR $<1 \mathrm{mg} / \mathrm{l}(n=29)$ & $\mathrm{PCR} 1-3 \mathrm{mg} / \mathrm{l}(n=43)$ & $\mathrm{PCR}>3 \mathrm{mg} / \mathrm{l}(n=42)$ & $p$ \\
\hline Idade (anos) & $68,4 \pm 5,1$ & $67,5 \pm 6$ & $67,8 \pm 5,8$ & 0,798 \\
IMC (kg/m²) & $26,6 \pm 4,6$ & $28,4 \pm 4,7$ & $30,3 \pm 4,8$ & 0,006 \\
Gordura corporal (\%) & $39,7 \pm 7,2$ & $42,5 \pm 10,1$ & $44,4 \pm 7,9$ & 0,098 \\
Cintura (cm) & $86,2 \pm 10,9$ & $90,2 \pm 15,4$ & $92,2 \pm 12,2$ & 0,178 \\
PA (mmHg) & & & & \\
- sistólica & $139,4 \pm 28$ & $145,2 \pm 23,8$ & $142,3 \pm 25,5$ & 0,652 \\
- diastólica & $84,2 \pm 16,6$ & $85,2 \pm 14$ & $85,1 \pm 18,6$ & 0,965 \\
Glicemia de jejum (mg/dl) & $82,9 \pm 14,8$ & $87,9 \pm 20$ & $90,8 \pm 19,9$ & 0,221 \\
Colesterol (mg/dl) & & & & \\
- total & $201,2 \pm 35,4$ & $210,7 \pm 47,4$ & $211,6 \pm 41,2$ & 0,554 \\
- HDL & $46,3 \pm 10,3$ & $46,2 \pm 11,5$ & $44,9 \pm 10,2$ & 0,827 \\
- LDL & $124,1 \pm 34,3$ & $136,2 \pm 50,4$ & $137 \pm 41$ & 0,410 \\
Triglicérides (mg/dl) & $153,6 \pm 85,1$ & $141,1 \pm 70,7$ & $147,7 \pm 67,9$ & 0,774 \\
\hline
\end{tabular}

PA: pressão arterial; PCR: proteína C-reativa; IMC: índice de massa corporal; HDL: lipoproteína de alta densidade; LDL: lipoproteína de baixa densidade. 
Tabela 3 estudados

\section{Correlação entre níveis de PCR e fatores de risco cardiovascular}

\begin{tabular}{lcc}
\hline Variáveis & $r$ & $p$ \\
Idade & 0,08 & 0,411 \\
IMC & 0,32 & $0,001^{*}$ \\
\% gordura corporal & 0,23 & $0,015^{*}$ \\
Cintura & 0,17 & 0,08
\end{tabular}

PA

$\begin{array}{lcc}\text { - sistólica } & -0,02 & 0,852 \\ \text { - diastólica } & -0,07 & 0,486 \\ \text { Glicemia de jejum } & 0,15 & 0,124 \\ \text { Colesterol } & & \\ \text { - total } & 0,16 & 0,091 \\ \text { - HDL } & -0,07 & 0,477 \\ \text { - LDL } & 0,16 & 0,083 \\ \text { Triglicérides } & 0,02 & 0,806\end{array}$

*Estatisticamente significativo.

PA: pressão arterial; PCR: proteína C-reativa; IMC: índice de massa corporal; HDL: lipoproteína de alta densidade; LDL: lipoproteína de baixa densidade.

A partir dos critérios adotados pela Sociedade Brasileira de Cardiologia (SBC) para a síndrome metabólica (SM) (26), não foi encontrada associação entre a presença desse quadro clínico e os níveis de PCR $(p=0,46)$. Tampouco houve associação entre o número de fatores presentes para esse diagnóstico, em cada indivíduo, e os níveis de proteína $C$ $(r=0,01 ; p=0,86)$.

\section{Discussão}

A mensuração de marcadores inflamatórios tem sido proposta para melhorar a predição de DCVs com base em fortes evidências do papel da inflamação na patogênese de tais eventos ${ }^{(20)}$. Estima-se que mais de um terço das patologias ocorra na ausência dos fatores de risco tradicionais ${ }^{(3)}$, que incluem hipertensão arterial (HA), lipoproteínas aterogênicas, exposição ao tabaco e hiperglicemia ${ }^{(1)}$. De acordo com os dados obtidos neste estudo, não foi verificada relação entre a PCR e os fatores de risco usualmente observados, à exceção do IMC $(r=0,32 ; p=0,001)$ e do percentual de gordura corporal $(r=0,23 ; p=0,015)$.

A existência de correlação entre a PCR e os fatores IMC e percentual de gordura corporal encontrada neste estudo está de acordo com um grande número de trabalhos que apontam para a existência significativa de associação entre proteína e mensurações de obesidade ${ }^{(6,}$ $7,10,13,14)$. Essa relação provavelmente se deve à produção de II-6 pelo tecido adiposo ${ }^{(28)}$. Estudos recentes indicam que a II-6 é também produzida pelos adipócitos in vivo, proporcionalmente à massa lipídica do indivíduo. Assim, o excesso de adiposidade poderia aumentar a expressão de II-6, elevando por conseqüência a expressão da PCR. Deste modo, elevações de PCR associadas à obesidade podem não estar relacionadas com estado inflamatório elevado ou progressão de aterosclerose. Entretanto, a PCR tem sido fortemente associada ao risco de eventos cardíacos, independente do $\mathrm{IMC}^{(7)}$.

Apesar de alguns autores apontarem a existência de correlação entre PCR e $\mathrm{HA}^{(2,13,10)}$, um estudo examinou polimorfismos do gene humano da PCR e observou que não há relação entre o aumento de $\mathrm{PA}$ e a variante genética que determina altas concentrações de PCR no soro do paciente, sugerindo que a associação observada em tais estudos sofreu interferência de outros fatores ${ }^{(25)}$. Kim et al. corroboram esse resultado demonstrando não haver correlação entre PCR e PA (e tampouco entre PCR e índices de variabilidade da PA nas 24 horas) em pacientes hipertensos ${ }^{(11)}$.

A associação praticamente nula entre PCR e idade encontrada neste estudo está de acordo com dados propostos na literatura, que afirmam não haver evidências relacionando esses dois parâmetros ${ }^{(2,3)}$. No que se refere aos níveis de TGs e HDL, os resultados obtidos entre os diferentes estudos são conflitantes. Alguns trabalhos afirmam existir associação entre PCR e tais fatores ${ }^{(2,10)}$; outros demonstram associação inexistente ${ }^{(7,12)}$. No entanto, muitos autores concordam com a inexistência de relação entre proteína com níveis de

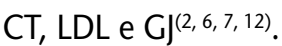

\section{Conclusões}

Os resultados encontrados neste estudo permitem concluir que a PCR esteve relacionada com marcadores de obesidade em mulheres idosas. Não houve, porém, evidências associando aos outros fatores de risco cardiovascular verificados (idade, hipertensão, perfil lipídico e glicemia alterados). Valendo-se do fato de que mais de um terço dos eventos cardiovasculares ocorre em indivíduos aparentemente saudáveis, e que estudos prospectivos comprovam a eficácia da PCR como marcador preditivo, o emprego da dosagem dessa proteína pode ser especialmente importante como ferramenta auxiliar na prevenção de tais patologias.

\section{Agradecimentos}

À BioSys LTDA e à Greiner Bio-One Brasil, pela doação do kit CRP-us Diasys e dos tubos para coleta a vácuo Vacuette, respectivamente. Ao Laboratório Exame, Novo Hamburgo, $\mathrm{RS}$, pelas dosagens de proteína C-reativa. 


\section{Referências}

1. ANAND, S. S. et al. C-reactive protein as a screening test for cardiovascular risk in a multiethnic population. Arterioscler Thromb Vasc Biol, v. 24, p. 1509-15, 2004.

2. BERMUDEZ, E. A. et al. Interrelationships among circulating interleukin-6, C-reactive protein, and traditional cardiovascular risk factors in women. Arterioscler Thromb Vasc Biol, v. 22, p. 1668-73, 2002.

3. DAVISON, S.; DAVIS, S. R. New markers for cardiovascular disease risk in women: impact of endogenous estrogen status and exogenous postmenopausal hormone therapy. J Clin Endocrinol Metab, v. 88, n. 6, p. 24708, 2003.

4. ELGHARIB, N. et al. C-reactive protein as a novel biomarker; reactant can flag atherosclerosis and help predict cardiac events. Postgrad Med, v. 114, n. 6, p. 39-44, 2003.

5. ERREN, M. et al. Systemic inflammatory parameters in patients with atherosclerosis of the coronary and peripheral arteries. Arterioscler Thromb Vasc Biol, v. 19, p. 2355-63, 1999.

6. HAK, A. E. et al. Associations of C-reactive protein with measures of obesity, insulin resistance, and subclinical atherosclerosis in healthy, middle-aged women. Arterioscler Thromb Vasc Biol, v. 19, p. 1986-91, 1999.

7. HEILBRONN, L. K.; NOAKES, M.; CLIFTON, P. M. Energy restriction and weight loss on very-low-fat diets reduce C-reactive protein concentrations in obese, healthy women. Arterioscler Thromb Vasc Biol, v. 21, p. 96870, 2001.

8. HIRSCHFIELD, G.; PEPYS, M. C-reactive protein and cardiovascular disease: new insights from an old molecule. QJM, v. 96, n. 11, p. 793-806, 2003.

9. IVASHCHENKO, Y. et al. Protein kinase $\mathrm{C}$ pathway is involved in transcriptional regulation of $C$ reactive protein synthesis in human hepatocytes. Arterioscler Thromb Vasc Biol, v. 25, p. 186-92, 2005.

10. KHERA, A. et al. Relationship between C-reactive protein and subclinical atherosclerosis - The Dallas Heart Study. Circulation, v. 113, p. 38-43, 2006.

11. KIM, K. I. et al. Association between blood pressure variability and inflammatory marker in hypertensive patients. Circulation, v. 72, p. 293-8, 2008.

12. LEMIEUX, I. et al. Elevated $C$ reactive protein: another component of the atherothrombotic profile of abdominal obesity. Arterioscler Thromb Vasc Biol, v. 21, p. 961-7, 2001.

13. MILLER, M.; ZHAN, M.; HAVAS, S. High attributable risk of elevated C-reactive protein level to conventional coronary heart disease risk factors: the Third National Health and Nutrition Examination Survey. Arch Intern Med, v. 165, n. 18, p. 2063-8, 2005.

14. PEARSON, T. A. et al. Markers of inflammation and cardiovascular disease: application to clinical and public health practice: a statement for healthcare professionals from the Centers for Disease Control and Prevention and the American Heart Association. Circulation, v. 107, n. 3, p. 499-511, 2003.

15. NISSEN, S. E. et al. Statin Therapy, LDL cholesterol, Creactive protein, and coronary artery disease. $N \mathrm{Engl} J$ Med, v. 352, p. 29-38, 2005.

16. O'ROURKE, F. et al. Current and future concepts in stroke prevention. Can Med Assoc J, v. 170, n. 7, p. 112333, 2004.

17. PAI, J. K. et al. Inflammatory markers and the risk of coronary heart disease in men and women. $N$ Engl J Med, v. 351, p. 2599-610, 2004.

18. PEPYS, M.; HIRSCHFIELD, G. C-Reactive Protein: a critical update. J Cli Invest, v. 111, p. 1805-12, 2003.

19. REILLY, M. P. et al. C-reactive protein and coronary artery calcification: the study of coronary atherosclerosis (SIRCA). Arterioscler Thromb Vasc Biol, v. 23, p. 1851-6, 2003.

20. RIDKER, P. M. C-reactive protein and other markers of inflammation in the prediction of cardiovascular disease in women. $N$ Engl J Med, v. 342, n. 12, p. 836-43, 2000.

21. RIDKER, P. et al. Comparison of C-reactive protein and lowdensity lipoprotein cholesterol levels in the prediction of first cardiovascular events. N Engl J Med, v. 347, n. 20, p. 1557-65, 2002.

22. RIDKER, P. M., WILSON, P. W. F.; GRUNDY, S. M. Should C-reactive protein be added to metabolic syndrome and to assessment of global cardiovascular risk? Circulation, v. 109, p. 2818-25, 2004.

23. SANTOS, W. B. Proteína C-reativa e doença cardiovascular: as bases da evidência científica. Arq Bras de Cardiol, v. 80, n. 4, p. 452-6, 2003.

24. SHLIPAK, M. G et al. Biomarkers to predict recurrent cardiovascular disease: the Heart and Soul Study. Am J Med, v. 121, n. 4, p. 50-7, 2008.

25. Smith, G. D. et al. Association of C-reactive protein with blood pressure and hypertension. Arterioscler Thromb Vasc Biol, v. 25, p. 1051-6, 2005.

26. SPOSITO, A. C. etal. IV Diretriz Brasileira sobre Dislipidemias e Prevenção da Aterosclerose: Departamento de Aterosclerose da Sociedade Brasileira de Cardiologia. Arq Bras Cardiol, v. 88, p. 2-19, 2007.

27. TSIMIKAS, S.; WILLERSON, J. T.; RIDKER, P. M. C-reactive 
protein and other emerging blood biomarkers to optimize risk stratification of vulnerable patients. JACC, v. 47, p. C19-C31, 2006.

28. YUDKIN, J. S. C-reactive protein in healthy subjects: associations with obesity, insulin resistance, and endothelial dysfunction: a potential role for cytokines originating from adipose tissue? Arterioscler Thromb Vasc Biol, v. 19, p. 972-8, 1999.

29. WANG, T. J. et al. Association of C-reactive protein with carotid atherosclerosis in men and women: the Framingham Heart Study. Arterioscler Thromb Vasc Biol, v. 22, p. 1662-7, 2002. 